\title{
Using tableaus to explore teachers' perceptions of how unequal power relations contribute to the spread of HIV and AIDS
}

\author{
Logamurthie Athiemoolam ${ }^{1, *}$, Naydene de Lange ${ }^{2}$, Mathabo Khau ${ }^{3}$
}

\author{
${ }^{1,3}$ Associate Professor, Nelson Mandela University, University Way, Port Elizabeth, South Africa \\ ${ }^{2}$ Professor, Nelson Mandela University, Port Elizabeth, South Africa
}

\begin{abstract}
The article explores pre-and in-service teachers' perceptions of how unequal power relations contribute towards the spread of HIV and AIDS. The sample, consisting of 19 teachers; 6 pre-service teachers from a Higher Education Institution and 13 in-service teachers from a rural primary school shared their views, through the use of tableaus, on how power relations between males and females contributed towards HIV and AIDS.The findings, emerging from the teachers' tableaus, demonstrated that they were aware of how gender identities contributed towards HIV and Aids.
\end{abstract}

Keywords- Acquiescent femininities, hegemony, gender-based violence, identities, masculinities, stigmatization.

\section{INTRODUCTIONAND BACKGROUND}

HIV and AIDS continue to pose a major challenge globally, but particularly to sub-Saharan Africa, in spite of the vast sums of money that have been spent to curb its proliferation, to intervene and to conduct research. The availability of antiretroviral drugs and a focus on the medical model, without an understanding of how the imbalance in gender power relations contributes to HIV transmission, is a futile exercise. Gender inequality, particularly in Africa, poses a major challenge, as highlighted by Wood (2013, p.51),since "women traditionally are accorded a low social status, denying them the ability to negotiate safe sex practices or to insist on marital fidelity." Although, it might be surmised, that women, who have higher levels of education, might be better predisposed to negotiate safe sex, this is not necessarily a reality for many educated women (Wood, 2013). Researchers and policymakers have long asserted that gender plays a role in vulnerability to HIV and AIDS and its impact across the globe (Fleshman, 2004; Interagency Coalition on AIDS and Development, 2006;Jewkes, Dunkle, Nduna \& Shai, 2010; Shisana et al., 2014). The socially defined and learned male and female behaviors serve to shape "the opportunities that one is offered in life, the roles one may play and the kinds of relationships that one
has"(Interagency Coalition on AIDS and Development, 2006, p.1). The gender roles, in particular, which reinforce and lead to the creation of inequality between men and women, leave women, vulnerable to HIV infection. This inequality makes it, especially difficult for women, to protect themselves against HIV infection. In sub-Saharan Africa, in particular, women are disproportionately impacted, where the 'feminization' of AIDS is most visible. The reasons why young women are disproportionately affected by HIV in the region are numerous and complex. According to research conducted by the United Nations Children's Fund (2015, p.23) high levels of transactional sex, between young women and men in Botswana, and age-disparate sexual relationships between young women and older men in Swaziland, increase young women's vulnerability to HIV. Ceteris paribus (holding all other factors constant), biologically, women are generally at a higher risk of contracting HIV/AIDS than men are (Higgins, Hoffman and Dworkin, 2010), and in this region, as pointed out by the Interagency Coalition on AIDS and Development (2006), for every HIV-positive young man (15-24 years) there are three HIV-positive young women.

The HIV and AIDS epidemic, which is one of the largest obstacles to development in South Africa, is destroying the lives of millions of people. About 6.4 million 
people, within a population of around 55 million are infected, with AIDS-related illnesses being the most common cause of death (Shisana et al., 2014). Furthermore, according to Cole (2015), over half of South Africans live below the national poverty line and more than $10 \%$ live in extreme poverty on less than $\$ 1.25$ (R15.85 per day).

The imbalance of power between the two sexes is most disturbingly articulated through gender-based violence, which enhances women's vulnerability to HIV and AIDS. Violence against women and girls can include rape and forced sex, physical assault, emotional abuse, humiliation or intimidation and economic restrictions (Interagency Coalition on AIDS and Development, 2006; Skinner, Hester \& Malos, 2013). Hence gender-based inequalities, not only affect women's vulnerability to HIV infection, but also exacerbate the negative effects of HIV and AIDS.

It is with this background in mind that this study aimed to explore how teachers, both pre- and in-service, understand how the power relations between males and females contribute to the spread of HIV. This article emanates from a larger study positioned in rural education and in the context of HIV and AIDS. The background to this study entitled 'New teachers for new times: Visual methodologies for social change in rural education in the age of AIDS',focused on an investigation into how the use of visual methodologies such as photovoice, collages, drawings and drama techniques, such as tableau, could lead to social change through conscientisation of the participants. This article specifically focuses on the participants engagement with the implementation of tableaux, as a visual methodology, to gain an understanding of how pre- and inservice teachers perceive unequal power relations between females and males as contributing towards HIV andAids.

Since teachers, by the nature of their work in schools, are at the forefront of prevention and intervention, they are positioned to make a difference in the prevention of HIV. To be able to do this, it is necessary that they themselves understand the inequality and power relations between men and women, and boys and girls, in the context of HIV and AIDS.The research question that guided this study was: What do tableaus reveal about teachers' perceptions of how gender power relations contribute to the spread of HIV?

\section{LITERATURE REVIEW}

\subsection{Teachers as preventive agents of HIV and AIDS in the context of the school}

Teachers are positioned as key role players in the prevention of HIV and AIDS in the context of the school and its learners (HEAIDS, 2010). The National Department of Education in South Africa (DoE, 1999, pp. 2-3) (now renamed Department of Basic Education, DBE) has a policy in place that provides guidelines that contribute "towards promoting effective prevention and care within the context of the public education system." This implies that teachers should not only be knowledgeable and able to teach about HIV prevention, but also know how to support learners in their classes, who are living with HIV, by ensuring their inclusion, optimal development and by protecting them against stigmatization. Although this responsibility is often delegated to Life Orientation teachers, it actually needs to be every teacher's concern (Helleve, Flisher, Onya, Mũkoma, \& Klepp, 2011). For this reason, it is imperative that all teachers, not only understand how HIV is spread, but also how it can be prevented and treated, and what drives the epidemic. While several social drivers of the epidemic have been identified (See Auerbach, Parkhurst, \& Cáceres, 2011), such as ignorance, education level, cultural differences, promiscuity, multiple partners, inequality, gender-based violence, and poverty, unequal power relations between females and males is a key driver of the epidemic in South Africa; which this study aimed to explore with the teachers (both pre- and inservice teachers). If teachers are aware of unequal power relations and understand how these play out in society, they might be better positioned to address the epidemic within the context of schooling.

\subsection{Theoretical perspectives of men and gender}

A focus on the social construction of gender has generated sophisticated literature on the gender identities of men and women, and masculinities and femininities. This has also led to men being included in the area of gender studies. The work of Connell has contributed significantly to our understanding of theoretical perspectives of masculinity and how it manifests in society in positions of power over femininity. Connell (1987) describes the existence of multiple configurations of masculinity that are hierarchically organized and structured, along the lines of gendered domination (of men over women, of powerful men over less powerful men, of adult men over younger men). She identifies one masculine position that is dominant and refers to this as hegemonic masculinity. It is this position that is 
generally associated with the subordination and oppression of women. The concept, based on Gramsci's work, refers to the exercise of power by creating consent through the establishment of accepted ideas or values (Jewkes \& Morrell, 2010).

In South Africa, hegemonic masculinity mobilizes and legitimates the subordination and control of women by men. It is thus an integral element of patriarchy, "the social organization that allocates, distributes and secures the power of men over women" (Jewkes \& Morrell, 2010, p.3). Hegemonic masculinity is associated with a set of practices, within the social system, which serve to both express and bolster men's power. The ideal of masculinity is thus achieved through a complex web of processes that extend into the organization of private life and cultural arrangements (Connell, 1987).This means that aspects of culture, religion and socially constructed institutions, such as the legal system, may work to preserve a particular cultural ideal of manhood, thereby reinforcing the status quo resulting in the marginalization of women and the concomitant imbalances that have characterized gender power relationships. In her argument, Connell contends that women somehow tend to uphold the status quo, relating to hegemonic masculinity, as there is no equivalent notion of hegemonic femininity, largely because there is more diversity in feminine ideals, although women are globally subordinated to men. She describes a form, or forms, of femininity which is characterized by compliance with women's subordination and an orientation towards accommodating the interests and desires of men. In this way, as highlighted by Jewkes \& Morrell (2010), women agree with the unequal structuring of relations, do not challenge these relations and eventually collude in the unequal distributions of gender power with men. While women, who support cultural ideals of such femininity, are rewarded, women who engage in acts of resistance can be marginalized and stigmatized (Jewkes \& Morrell, 2010).

An understanding of hegemonic masculinity and emphasized femininity is crucial to an interrogation of the gender power relations that contribute to the spread of HIV in South African society, since the manner in which society is configured, contributes to identity construction.

South African masculinities valorise the martial attributes of physical strength, courage and toughness and an acceptance of hierarchical authority; but most of all, they demand that men are able to exercise control over women and other men (Morrell, 1998). Within relationships with women, the expectations of establishing control provide space for the use of physical and sexual violence against women, in efforts both to achieve and demonstrate this (Jewkes \& Morrell, 2010).

\section{RESEARCH METHODOLOGY AND DESIGN}

\subsection{Research approach}

In this qualitative study, located in an interpretive paradigm, an arts based methodology, referred to as performative inquiry, that shares characteristics of ethnodrama (Fels, 2004), was used.The use of drama-in-education methods to generate data has burgeoned worldwide, but also in South Africa, more recently, particularly in the field of education in addressing issues related to HIV and AIDS, gender-based violence, and sexuality (see for example, Mitchell, 2008).

According to Fels (1998), performative inquiry is a research methodology that uses the medium and processes of drama as a way of knowing. This methodology uses performance (improvisation, tableaux, role drama and playbuilding) to create a co-evolving interaction among participants, their environment and the subject theme within which moments of learning emerge (Fels, 2004). Tarlington and Michaels (1995) describe tableau as a method in which the group collectively creates a scene around a particular issue or theme. Within the context of this study, the theme focusedonhow power relations contributed to the exacerbation of HIV and AIDS. Toye and Prendiville (2000, p.117) describe a tableau as "a still picture of a key moment frozen in time". The participants' expressive faces, body positions and how they pose in relation to each other create a living picture or sculpture. Tableau, as method, was selected, for the purposes of this study,as it enables the participants to develop their perceptions on an issue, activate and build on background knowledge, ask inquiring questions, determine what is important, and synthesis and, if necessary, reframe their viewpoints.

The participants, within in the context of this study, were therefore involved in performative inquiry, in particular through the creation of tableaux. The aim of the tableau building exercise was to enable the participants to create frozen moments or scenes, which, according to them, most effectively portray how power relations between men and women contribute to the spread of HIV in society at large. The participants, in each of the tableaus, were questioned by the observers (participants of the other groups) to establish the context of the tableau, who they were and what was 
happening in the scene in order to examine and interrogate the main themes highlighted.

The use of tableaux as a strategy to generate data on how power relations contribute to the spread of HIV provided a safe space for participants to engage with the topic. Since the issue of power relations tends to be invasive, sensitive and personal, the use of tableaux provided the necessary distance for the participants to interrogate their key concerns in a more detached manner. Furthermore, the participants' active involvement in the creation and processing of the tableaux encouraged engagement, sharing of experiences and discussion of how gender power relations contribute to the spread of HIV. The sharing of personal insights, based on the tableaux, led to learning about the topic, which facilitated a deeper interrogation of the issue of gender power relations and HIV. The direct involvement of the teachers in the creation of tableaux enabled them to identify how power relations manifested within their contexts and to reflect on how to be more empathetic to the victims of hegemonic masculinity, within society at large, and to consider strategies that they could implement to challenge and deconstruct hegemonic masculinity and acquiescent femininities. The use of participatory methods, such as tableaux, contributed to an in-depth understanding of the issue of power relations and HIV and Aids, as the participants worked collaboratively to share insights based on their experiences.

\subsection{Participants}

The participants comprised two groups of teachers, namely, in- and pre-service teachers. The in-service teachers were teachers, who taught at a rural primary school within the Nelson Mandela Metropole. The farm school was purposively selected for the project entitled 'New teachers for new times: Visual methodologies for social change in rural education in the age of AIDS'. The pre-service teachers were Intermediate Phase teachers from an institution of higher education, within the Nelson Mandela Metropole, and not from a rural context. All fourth year Intermediate Phase pre-service students were invited to participate in the project and six volunteered to teach in the farm school over a twoweek period of school-based learning, as part of the project. Thirteen staff members from the school (the entire staff) and the six pre-service teachers participated voluntarily. The inservice teachers comprised 12 African females and one African male (the entire staff), while the pre-service teachers comprised three females (two 'Coloured' and one White) and three males (one Black African, one 'Coloured' and one
White). The pre-service teachers' ages ranged from 21 to 30 , while the in-service teachers' ages ranged from 40 to 58.The pre-service teachers were all in their final year and were about to graduate, while the in-service teachers had the following qualifications; 7 had a three year Diploma in Education, 5 had a degree, and 1was registered for an Honors degree. The marital status of the pre-service teachers' group was that 5 were unmarried, 8 were married or had a partner, and 2 were single. None of the 6 in-service teachers were married. The sample, for the purposes of this study, thus comprised 19 participants.

\subsection{The research process}

During the course of the project we had been using various visual methods, such as drawing (see Theron, Mitchell, Smith \& Stuart, 2011) and photovoice to address HIV and AIDS issues within the school (De Lange, Khau \& Athiemoolam, 2014). During this workshop the in- and preservice teachers were exposed to the processes and practices involved inthe creation of tableaus with a specific focus on issues relating to HIV and AIDS. The workshop took place on a Friday afternoon, from 15:00 to 19:00, at a non-school venue. After a hands-on practical experience,focusing on the creation of tableaus, the participants were divided into four mixed groups (comprising both in- and pre-service teachers) with the brief that they had to create a tableau that focused on gender power relations and HIV and AIDS. The prompt that served to guide the creation of the tableau was: How do gender power relations lead to the spread of HIV?

They were given 45 minutes to plan their tableau. Thefour tableaus were presented and the audience; comprising the other groups of participants, who observed the tableaus, posed questions to gain an understanding of the context of the tableau and the message that it intended conveying. After all the groups presented their tableaus to the participants on the theme, the group reflected collectively on the insights gained from the tableaus and how they resonated with their own experiences, within their own contexts. The tableaus and the reflections were video-taped, transcribed and analyzed thematically (Braun and Clark, 2006).

\subsection{Ethical measures}

Ethical measures involved obtaining ethical clearance from the Nelson Mandela Metropolitan University's Ethics Committee to conduct the research (H10-EDU-ERE-004), permission from the Department of Education to conduct research in the particular rural primary school, and informed 
consent from all the participants, who participated in the study, in writing. The participants' anonymity was ensured by not using their names or referring to them directly and the informed consent form indicated that they could withdraw at any time during the research process, if they wished to do so.

\section{FINDINGS}

This section provides a description of each of the tableaus presented by the four groups and highlights some of the key themes that emerged from the participants' analysis of the scenes during the group reflection session. The main themes depicted by the tableaus, focusing on how unequal power relations between males and females could lead to the spread of HIV and Aids, include male infidelity, gender-based violence, stigmatization and discrimination, and poverty and prostitution. These themes will be discussed in terms of how the participants portrayed them, within the context of their individual tableaus, and with reference to reflections based on the participants' experiences.

\subsection{Male infidelity}

The first tableau, which comprised five characters, represented a scene which depicted two women standing over a crying woman, with another one pointing a finger at a man, who was seated, and who looked forlorn. Other participants, who were not part of the group, posed questions to the characters in the tableau to unravel the scene and to establish what was happening in the scene as a whole. It emerged, from their questioning, that the scene portrayed a woman, who was infected with HIV, by her husband. The two women, standing over her, were the neighbors trying to console her, and the third woman, was her sister who blamed the husband for infecting his wife, as depicted in the tableau by her pointing a menacing finger at him. Through questioning the protagonist it transpired that she was a dedicated wife and mother to her husband and children, but that her husband disappointed her by having extra-marital affairs.

Through the process of thought tracking to establish what the chief protagonist was thinking at the given moment in time, other participants attempted to voice what they thought she was thinking. The protagonist then indicated by nodding her head which thought came closest to what she was thinking. Six participants articulated their lines as follows' "I am frustrated/I should have used a condom/I am devastated/this is the end of the world/I am extremely depressed and I trusted him. "She dismissed the first five thoughts, with a negative nod of the head, and accepted the last one with a positive nod of the head. Through a process of elimination, the participant observers were able to establish that the main thought in the crying woman's mind was, ' $I$ trusted him'. The scene, in brief, thus depicted a HIV positive woman, who was disappointed with her husband because he broke her trust, by having extra-marital affairs and infected her with the virus.

\subsection{Stigmatization and discrimination}

In the second tableau, the group presented a tableau, comprising 4 participants; in the scene a crying girl was bent over two lifeless bodies, while a boy had his back towards the crying girl and appeared to be disinterested and disconnected. In trying to unravel the frozen scene, one of the group members asked the crying girl why she was crying, to which she replied, 'My parents are dead, now I am all alone'. She later explained that both her parents had died of AIDS-related illnesses and that there was no one else to take care of her. When she was questioned about the boy, who had his back towards her, it transpired that he was her boyfriend, who had shunned her. When the boy, in the tableau, was asked by one of the other participant's, in her role as the observer, 'But why have you turned your back on her now that she is alone', he nonchalantly replies, 'She was my girlfriend, but no longer can be, because I don't want to be infected by HIV and AIDS, as her parents died of the disease.' Using the process of thought tracking it emerged that the protagonist's greatest concern, at that moment in time was, 'Why did you leave me? I'm so lonely now. 'In this scene a young girl had become an AIDS orphan, as both her parents had died of AIDS related illnesses and her boyfriend rejected her, because he felt that he would also be infected by the virus.

In analyzing the scene, one of the participant's, from the group of observers, highlighted the fact that the child was being isolated from both her parents and her friends. Another participant added that, "The child could now look for love in other places, become promiscuous, have unprotected sex, abuse drugs and alcohol", while another observer added "And even commit suicide".

It was clear from their depiction of the scene through the tableau that the group aimed to highlight how people can be discriminated against, and even stigmatized, when other members of their family succumb to HIV and Aids.

\subsection{Gender-based violence}


The third tableau, comprising 5 characters, portrayed a tableau in which a woman was holding a man back to prevent him from striking another woman with his fist. Two other men, who were present and looked on, tried to intervene. Through a session of questioning the characters, it emerged that a man was trying to beat his wife, while a police woman (the woman who was holding him back)was trying to intervene to stop him from injuring her. The other two men, in the scene, who were observing, were neighbors; one of whom telephoned the police, after he heard his neighbor's wife screaming. When the woman, who was being beaten, was questioned as to what was happening, she replied as follows, 'My husband came home drunk and he is beating me'. In response to one of the participant's questions relating to why her husband is being so aggressive towards her, she replied, 'When I asked him for money to buy food for me and the children, he just beat me up'. In a further question posed by another observer, relating to why she did not leave her husband, she candidly replied, 'But how can I leave him, I love him'. When one of the other observers asked the police woman what she was thinking and what was on her mind, she responded that she had to contend with gender based violence on a daily basis, as it was a normal occurrence.

The tableau thus depicts a scene focusing on gender based violence, where both patriarchy and intoxication have a role to play in subordinating the protagonist. In spite of his constant abuse of her; she does not want to leave him, because she maintains that she loves him; which could also signify that she may be dependent on him.

\subsection{Poverty and prostitution}

In the fourth tableau, comprising five characters, a woman is positioned with her back towards three other girls, who looked depressed and forlorn; two girls were holding hands, while the third one was separated from the other two; standing on her own. The woman was accompanied by a man, who was holding her hand. The tableau depicts disconnectedness between the couple and the three girls. When the woman was questioned as to who the three girls were and why she had her back towards them, she responded as follows, 'I am the mother of these 3 children. My husband has died, now I am on the streets'. When the man, who was holding the woman's hand, was asked, who he was and what he was doing in the scene, his response was, 'I am one of the guys who normally picks her up on the street and I want to sexually abuse her'. When the children were asked about their situation and how they felt,it was discovered that the older daughter, who was extremely angry, was looking after the youngest child, who was crying because as she said, 'I am cold and hungry'. One of the children, who was separated from the other two, when asked why she was on her own responded as follows, 'My mother left me and pushed me out'. In a nutshell, the tableau depicts a scene of a mother of three children who neglected her children, because she has had to turn to prostitution, after the death of her husband.

\subsection{Participants' comments based on the four images}

In their analysis of the four tableaus, a number of the participants mentioned that the scenes tended to depict gender dynamics in South African society at large. One of the participants referred to two of the tableaus namely the one where the husband infects his wife due to his infidelity (see 4.1), and the one where the husband beats his wife to demonstrate the power that he exerts over her (4.3); as tableaus representative of the gender dynamics within South Africa. One of the participants, in reflecting on the tableaus, commented that they were realistic portrayals of the malefemale gender power relations in South Africa, in that they "showed a lack of power on the part of women and the power that men had over women in society". Another participant identified the "different types of violence directed against women such as physical and emotional abuse and physical neglect." According to one participant, the focus on the patriarchal society that tends to characterize South Africa society, was highlighted by "the way women in the tableaus were either marginalized or discriminated against."

Another participant was vocal in her concern for the plight of the girl child within society, as depicted in the tableaus, since all the scenes either depicted girls, who were abandoned by their parents, or who were left on their own to fend for themselves. In reflecting on the tableaus, the participants indicated that they tried to portray their tableaus as realistically as possible, based on their experiences. This was aptly summed up by one of the participants when she said, "The way we portrayed it is the way we see it."

One of the participants, in reflecting on the role of the schools in supporting those learners living with HIV and AIDS, emphasized that schools needed to demonstrate a level of "empathy and willingness to listen and to be there," which could be realized by motivating schools to "take their rightful place as the centre of care and support." Another participant emphasized the importance of teachers working collaboratively to create a "community of worth, where 
children feel valued and supported for who they are and are not judged by the factors beyond their control such as poverty or HIV infection. 'In creating a safe space, where children are respected and nurtured, it was suggested by one of the in-service participants that all teachers should aim to create a school environment where children are valued and appreciated for who they are, and not by their socioeconomic background or other factors beyond their control.

\section{DISCUSSION}

It was evident from an analysis of the four tableaus that gender imbalances, with a specific focus on male hegemony, were predominant. The main themes highlighted in the tableaus focused on male infidelity, gender-based violence, and poverty, prostitution and parental neglect. The discussion will focus on the ways in which hegemonic masculinity and the unbalanced gender power relations, as depicted in the tableaus, could lead to the spread of HIV and AIDS in society at large.

The four scenes presented, focused on the unequal power relations between males and females. In both the first and the fourth tableaus male sexual power over women was clearly depicted, Whilst in the first tableau, male sexual power was highlighted through male infidelity, as a husband was responsible for infecting his wife with HIV due to his sexual promiscuity, the fourth tableau depicts this power when a male who 'picks up a prostitute', is quite vocal about his intentions of wanting to 'sexually abuse the woman'.

Within the context of the first tableau, the husband's sexual relationships with multiple partners could also be ascribed to gender norms where men may be allowed to have more than one partner, but not women (Kimmel, 2004). This further validates the manner in which male hegemony is manifested in society at large. According to Parker et al.(2007), evidence from South African studies shows that some gender norms, related to masculinity, encourage men to have more sexual partners and older men to have sexual relations with much younger women. This contributes to higher HIV infection rates among young women, especially those aged between 15 and 49 years, compared to young men (Harrison, 2005; Human Science Research Council, 2009; Shisana et al., 2014).

In terms of power relations, a man may expect to lead and control sexual relations and may force his woman partner to comply. This unbalanced power relationship, may make him believe that he is entitled to have sex with other women, yet expect his wife to remain faithful (Jewkes \& Morrell, 2010). According to Jewkes (2002, p.1092), "ideas of male sexual entitlement "often legitimize the sexual violence, which occurs in marriages and families. Men, who engage in transactional sex, are more likely to be physically violent and abusive towards their partners, to have large numbers of partners and are prone to rape (Jewkes et al., 2006a). Holland et al. (1998, p. 11), also conclude that there is a belief in many societies that "women's desires and the possibility of female resistance are potentially unruly forces to be disciplined and controlled, if necessary by violence". Such a view serves to justify male sexual violence against women and positions it as legitimate.

Male hegemonic power is also illustrated in the third tableau, when a husband physically abuses his wife. According to Mutinta et.al (2011) violence against women such as physical and sexual violence, increase women's vulnerability to HIV. According to Jewkes \& Morrell(2010), in some instances, women may tolerate violence from their husbands and boyfriends and may even accept their partners just to remain in the relationship. This is supported by cultural wisdom such as the saying that beating is a sign of love'. The fact that the protagonist, in one of the tableaus, says that she does not want to leave her husband, because she loves him, is indicative of the fact that she may have accepted the beatings as a sign of his love for her. This dominant form of femininity, also referred to as acquiescent femininity, requires women to be strong, andable to accept and cope with the stresses life brings, including those caused by women's subordinate position in their relationships. According to Jewkes \& Morrell (2010), within the South African context, acquiescent femininity and hegemonic masculinity are both cultural ideals which are upheld by a system of sanctions and rewards.

Violence is a consequence of gender power inequities at both a societal and relationship level, and also serves to reproduce power inequities (Van der Stratenetal., 1998). Qualitative research has shown that the links between HIV and AIDS, gender inequity and gender-based violence lie in the patriarchal nature of society and ideas of masculinity that are based on the control of women and that celebrate male strength and toughness (Maman etal., 2002). According to Strebel etal. (2006), such culturally sanctioned gender roles are intimately connected with both gender-based violence and HIV risk. These ideals lead to risky sexual behaviors, predatory sexual practices and other acts of violence against women (Shisana etal., 2009). They also 
allow men to have multiple partners and control their sexual encounters. Emerging evidence from South Africa and India shows that men, who perpetrate violence, are more likely to be HIV infected (Jewkes etal., 2009). In the context of South Africa, for African women, excusing male behaviour is an integral part of dominant femininity and essential for holding onto their husbands. Although individual women might resist male power, the majority of women, especially in developing countries, succumb to these practices (Pettifor et al, 2004). Violence prevents women from influencing the circumstances of sex, resulting in more frequent sex and less condom use (Jewkes etal, 2006b). The findings of the study conducted by Jewkes etal. (2010),into the relationship between intimate partner violence and incidence of HIV infection in young women in South Africa, revealed that rural South Africa women, who were subjected to intimate partner violence and high gender inequity in relationships, experienced an increased incidence in HIV infection. This study by Jewkes etal. (2010) provides strong temporal evidence to support a causal association between intimate partner violence or relationship inequity and new HIV infection.

The findings of another study, conducted by Harris et al. (2006) on gender and HIV and AIDS, reveal that fear and experiences of violence make women reluctant to ask their partners to use condoms or refuse unprotected sex. Previous studies show that gender and gender inequality are among the risk factors for the spread of HIV and AIDS (Harris et al., 2006; Human Sciences Research Council, 2009; South African Institute of Race Relations, 2009).

Women's exposure to gender inequity and violence is often related to complicity with an ideal of hegemonic masculinity. According to Jewkes \& Morrell (2010), when women are acquiescent and accept male control and violence, their behavior is considered as a trade-off made from and expectation of social (or financial) reward. The degree to which women are able to risk losing these rewards differs according to other dimensions related to their material and emotional vulnerability. Thus the poorest and most marginalized women, and those who may have been rendered vulnerable in other ways, such as by abuse in childhood, may be least able to demonstrate resistance to patriarchy, thereby passively accepting their subordinating position to men. There is a growing body of evidence which suggests that women, who have experienced more gender power inequity in their relationship and gender violence, are at greater risk of HIV. Since men, who have been violent are more likely to be infected, it seems that women are least able to protect themselves when in relationships with men who pose the greatest risk for them (Jewkes \& Morrell, 2010).

In the third tableau, a young girl is discriminated against and stigmatized by her boyfriend, after both her parents succumb to HIV and AIDS. The process of stigmatization helps to create a sense of control and immunity, at both the individual and group level, as it distances people (and their in-groups) emotionally from risk. According to Deacon et al. (2005), the identification of the out-group, is highly variable, as it depends on personal identities and historical power relations. In instances, for example, where a particular group of stigmatizing ideas is validated by a powerful person or group and deployed as part of broader power struggles, "it becomes pervasive, entrenched and very difficult to shift"(Deacon et al., 2005, p.23). Dominant group or individual 'othering', as highlighted in the tableau by the boyfriend's stigmatization of the protagonist, is extremely powerful in society as it could militate against other representations and even cause widespread self-stigmatization. Since the stigmatized protagonist, represented in the tableau, feels 'lonely' and dejected, there is a greater risk of self-stigmatization, which could impact negatively on her self-esteem, emotional and psychological well-being.

Education programmes have a significant role to play in challenging stigmatizing beliefs and informing PLHIV (People living with HIV) about rights and services. According to Brown etal. (2001), the most effective education interventions should take local contexts into account, be community based and link skills building, counseling and social interaction programmes in relevant ways. People may be more likely to express stigmatizing views and discrimination based on these views, if they are widely shared and openly accepted in society. According to Deacon et al.(2005, p.81) education interventions need to indicate that stigma is a social problem and not only a problem of individual ignorance.

In the fourth tableau, a further issue that is explored relates to how parents, in this case the mother, can sometimes neglect her children, as she does not have the means to support them. In this particular tableau, the mother is depicted as being unable to take care of her children, as she has to earn a living as a sex worker. Johnson \& Budlender (2002) argue that, as a result of a lack of resources, people could offer their bodies for financial gain in order to make ends meet and hence engage in unprotected 
sexual intercourse. The power imbalance between males and females, as highlighted in this tableau, translates into economic dependency for women. Since, as pointed out by the Interagency Coalition on AIDS and Development (2006, p.1), men have greater control and access to productive resources than women, especially in developing countries, they maybe "forced to exchange sexual favours for money or gifts in order to meet their basic needs, support their families, pay for school or even to enhance their social power". In this way sex is used as a commodity and survival strategy and women, who are most vulnerable materially and emotionally, are least able to reject them and thus most vulnerable to male violence and control and consequently HIV.

Male violent and risky sexual practices flow from dominant ideals of masculinity. Women's exposure to these is related to their adoption of femininities that forgive and accommodate male gender-inequitable and anti-social behavior. The unfair gender power relations, which promote male hegemony and acquiescent femininity, will need to be addressed if the AIDS pandemic is to be averted. Ending the pandemic both exposes systems of injustice and presents an historic opportunity for real change (Interagency Coalition on AIDS and Development, 2006, p.4). This means that entrenched cultural beliefs and intensely held personal norms for both men and women need to be interrogated, debated and analyzed, so that women are afforded the opportunity to enjoy the same rights as their counterparts. If this is to be realized, men will need to "learn about and dismantle the parts of their gender conditioning that have resulted in the development of inappropriate power over women" (Interagency Coalition on AIDS and Development, 2006, p.4). This implies that a climate of encouragement and understanding will have to characterize the power relations if this relationship is to be transformed. Hence women need to continue to empower and protect themselves, speak out against sexual and gender oppression and to embrace a sense of agency if the differences in power dynamics are to be addressed.

Since men have more control over decisions relating to sex, it is their behavior that will determine how quickly and to whom the virus is transmitted. Prevention measures should thus focus on targeting men and boys, as they have the power, through their informed decisions on sex, to promote both their own health and the health of women and girls. To turn the tide of HIV and AIDS, it is thus crucial that men take responsibility for their actions. For this to be realized, change needs to begin with the way boys are raised, which implies confronting certain cultural attitudes and beliefs that have traditionally encouraged risk-taking and discrimination against women (Coalition on Aids and Development, 2006).

In order to address the inequality in society we need to focus on changing the bigger picture, rather than concentrating solely on trying to change individual behavior. This implies aiming to build more gender-equitable and caring masculinities and less acquiescent femininities. Interventions are thus needed at policy, service, community and individual levels. Both policy changes and service strengthening are required to effectively enforce legislation that protect women and girls from gender-based violence, and which promotes effective care, legal redress and protection for survivors. There is also a need for initiatives at all levels to encourage men's involvement in the care economy by promoting them as fathers, both financially and socially, in the lives of their children.

\section{CONCLUSION}

The use of tableaus in this arts based research has enabled the group of teachers in this study to articulate their understanding of how unequal power relationships contribute to the spread of HIV and Aids. The research was not designed to establish causal relationships between unequal power relations and the spread of HIV, as that has been established in several other studies, as we have pointed out, but to explore, with the teachers, their understanding of unequal power relations in the spread of HIV and through the work with them, deepen their understanding thereof.

It is evident, from the findings of the research, that the teachers, who participated in the study, from both rural and urban areas, demonstrated through their tableaus that hegemonic masculinities and acquiescent femininities could contribute significantly to the spread of HIV in that when men exert their sexual power and status over women, they make them subservient and deny them of a voice. Since the ideals of femininities are embedded in cultural processes that reward compliance, it is vital to interrogate and question how these cultural processes manifest in society at large and how they could be challenged. It is through such work, with teachers, as demonstrated in the study, that their awareness of the influence of unequal power relations in the spread of HIV is raised and articulated, which enables them to empower both themselves and their learners. 


\section{REFERENCES}

[1] Auerbach, J. D., Parkhurst, J. O., \& Cáceres, C. F. (2011). Addressing social drivers of HIV/AIDS for the long-term response: conceptual and methodological considerations. Global Public Health, 6(3), 293-309.

[2] Braun, V., \& Clarke, V. (2006). Using Thematic Analysis in Psychology. Qualitative Research in Psychology, 3, 77-101.

[3] Brown, L., Trujillo, L \& Macintyre, K. (2001). Interventions to reduce HIV/AIDS stigma. What have we learned? New Orleans: Horizons Programme.

[4] Cole, M. (2015). Is South Africa operating in a safe and just space? London: Oxfam.

[5] Connell, R.W. (1987). Gender and Power: Society, the person and social politics. Palo Alta, California: University of California Press.

[6] Deacon, H., Stephney, I., Prosalendis, S. (2005). Understanding HIV/AIDS stigma: A theoretical and methodological analysis. Cape Town: HSRC.

[7] De Lange, N., Khau, M., Athiemoolam, L. (2014). Teaching practice at a rural school ? 'And why should we go there?' South African Journal of Higher Education. 28(3), 748-766.

[8] Department of Education (DoE) (1999). National policy on HIV/AIDS, for learners and educators in public schools, and students and educators in further education and training institutions. Pretoria: Department of Education.

[9] Fels, L. (1998). In the wind clothes dance on a line. Journal of Curriculum Theorising, 14(1),27-36.

[10] Fels, L. (2004). Complexity, teacher education, and the restless jury: Pedagogical moments of performance. Complicity: An international journal of complexity and education, 1(1). http://www.complexityandeducation.ualberta.ca/publications.h $\underline{\mathrm{tm}}$ (accessed April 15, 2016)

[11] Fleshman, M. (2004). Women: The face of AIDS in Africa. Africa Renewal, 18(3), 6-8.

[12] Harris, M., Michael, J., Christine, R \& Dale, G. (2006). Gender differences in risk assessment: Why do women take fewer risks than men? Judgement and decision making, 1(1), 48-63.

[13] Harrison, A. (2005). Young people and HIV/AIDS in South Africa: Prevalence of infection, risk factors and social context. In S.S. Abdool-Karim \& Q.A. Abdool-Karim (Eds.), HIV/AIDS in South Africa (pp. 262- 284). Cambridge: Cambridge University Press.

[14] HEAIDS (2010). HIV and AIDS in Teacher Education Evaluation Report of a Pilot Project in South African Higher Education Institutions. Pretoria: Higher Education South Africa.

[15] Helleve, A., Flisher, A. J., Onya, H., Mũkoma, W., \& Klepp, K. I. (2011). Can any teacher teach sexuality and HIV/AIDS? Perspectives of South African Life Orientation teachers. Sex Education, 11(01), 13-26.
[16] Holland, J., Ramazanoglu, C., Sharpe, S., and Thomson, R. (1998). The male in the head: Young people, heterosexuality and power. London: Tufnell Press.

[17] Higgins, J., Hoffman, S., and Dworkin, S. (2010). Rethinking gender, heterosexual men,

[18] and women's vulnerability to HIV/AIDS. American Journal of Public Health, 100(3), 435-445.

[19] Human Sciences Research Council (HSRC). (2009). South African national HIV prevalence, incidence, behavior and communication survey, 2008: A turning tide amongst teenagers? Pretoria: Human Science Research Council.

[20] Interagency Coalition on AIDS and Development. (2006). HIV/AIDSand gender issues.http://www.icadcisd.com/pdf/Gender_Issues_EN_FINAL.pdf(Accessed February 2, 2016).

[21] Jewkes, R. (2002). Preventing sexual violence: A rights-based approach. The Lancet, 360, 1092-1093.

[22] Jewkes, R.\& Morrell, R. (2010). Gender and sexuality: emerging perspectives from the heterosexual epidemic in South Africa and implications for HIV risk and prevention.Journal of the International AIDS Society, 13(6), 111.

[23] Jewkes, R., Dunkle, K., Koss, M.P., Levin, J., Nduna, M., Jama, N\& Sikweyiya, Y.(2006a). Rape perpetration by young rural, South African men: prevalence, patterns and risk factors.Social Science and Medicine, 63, 2949-61.

[24] Jewkes, R., Dunkle, K., Nduna, M.(2006b). Factors associated with HIV sero-status in young rural South African women: Connections between intimate partner violence and HIV.International Journal of Epidemiology, 35, 1461-68.

[25] Jewkes, R. Sikweyiya, Y., Morrell, R.\& Dunkle, K. (2009). Understanding men's health and use of violence: interface of rape and HIV in South Africa. Pretoria: Medical Research Council.

[26] Jewkes, R., Dunkle, K., Nduna, M\& Shai, N. (2010). Intimate partner violence, relationship power inequity and incidence of HIV infection in young women in South Africa: a cohort study. The Lancet, 376, 41-48.

[27] Johnson, L. \& Budlander, D. (2002). HIV risk factors: A review of the demographic, socio-economic, biomedical and behavioural determinants of HIV prevalence in South Africa. Cape Town: University of Cape Town (Centre for Actuarial Research).

[28] Kimmel, M.S. (2004). The gendered society.(2 ${ }^{\text {nd }}$ Ed.) New York: Oxford University Press.

[29] Maman, S., Mbwambo, J.K., Hogan, N.M., Kilonzo, G.P., Campbell, J.C., Weiss, E\& Sweat, M.D. (2002). HIV positive women report more lifetime partner violence: Findings from a voluntary counseling and testing clinic in Dar es Salaam, Tanzania.American Journal of Public Health, 92(8), 13311337.

[30] Mitchell, C. (2008). Getting the picture and changing the picture: Visual methodologies and educational research in 
South Africa. South African Journal of Education, 28(3), 365383.

[31] Morrell, R. (1998). Of boys and men: Masculinity and gender in Southern Africa.Journal of Southern African Studies, 24, 605-630.

[32] Mutinta, G., Gow, J, George, G., Kunda, K \& Ojieg, K. (2011). The influence of socio-economic determinants on HIV prevalence in South Africa. Toronto: Academic Research Centre of Canada.

[33] Parker, W., Makhubele, B., Ntabalati, P.\& Connolly, C. (2007). Concurrent sexual partnerships amongst young adults in South Africa: Challenges for HIV prevention communication. Pretoria: Centre for AIDSDevelopment, Research and Evaluation.

[34] Pettifor, A.E., Measham, D.M., Rees, H.V. and Padian, N.S. (2004). Sexual power and HIV risk, South Africa: Unequal sexual power reduces condom use in South Africa. https://www.ncbi.nlm.nih.gov/pmc/articles/PMC3328992/ (Accessed 20 January 2017).

[35] Shisana,O.,Rehle, T.,Simbayi, L.C.,Zuma, K., Jooste, S.,Pillay-van-wyk V.,Mbele, N.,Van Zyl, J., Parker,W.,Zungu, N.P \& Pezi, S. the SABSSM III Implementation Team. (2009). South African national HIV prevalence, incidence, behavior and communication survey 2008: A turning tide among teenagers. Cape Town: HSRC Press.

[36] Shisana, O., Rehle, T., Simbayi, L C., Zuma, K., Jooste, S., Zungu, N., Norman, J. (2014). South African National HIV Prevalence, Incidence and Behaviour Survey, 2012. Cape Town, South Africa: HSRC Press.

[37] Skinner, T., Hester, M., \& Malos, E. (Eds.). (2013). Researching gender violence. Devon, UK: Willan Publishing.

[38] South African Institute of Race Relations. (2009). Living conditions and communications: South Africa Survey 2007/8. Pretoria: South African Institute of Race Relations.

[39] Strebel, A., Crawford, M., Shefer, T., Cloete, A., Henda, N., Kaufman, M., Simbayi, L., Magome, K\& Kalichman, S. (2006). Social constructions of gender roles, gender-based violence and HIV/AIDS in two communities of the Western Cape, South Africa.Journal of Social Aspects of HIV/AIDS, 3(3), 516-528.

[40] Tarlington, C. \& Michaels, W. (1995). Building Plays. Toronto: Pembroke Press.

[41] Theron, L. C., Mitchell, C., Stuart, J., \& Smith, A. (Eds.). (2011). Picturing research: Drawings as visual methodology. Rotterdam, the Netherlands: Sense Publishers.

[42] Toye, N.\& Prendiville, F. (2000). Drama and traditional story for the early years. London: Routledge Falmer.

[43] United NationsChildren'sFund. (2015).Synthesis report of the rapid assessment of adolescent and HIV programme in five countries: Botswana, Cameroon, Jamaica, Swaziland and Zimbabwe. New York: UNICEF.
[44] Van der Straten, A., King, R., Grinstead, O., Vittinghoff, E., Serufilira, A. \& Allen, S. (1998). Sexual coercion, physical violence and HIV infection among women in steady relationships in Kigali, Rwanda.AIDS and Behavior, 2(1) ,6173.

[45] Wood, L. (Ed). (2013). Dealing with HIV and AIDS in the classroom. Cape Town: Juta \& Company. 